\title{
Los Comentarios reales y la historiografía española, indiana y humanista
}

Song NO / Purdue University

\section{Resumen}

Los Comentarios reales del Inca Garcilaso (1539-1616) abarcan tres tradiciones historiográficas: primero, la tradición de crónicas españolas; segundo, la historiografía latinoamericana que comenzó después del "Descubrimiento" del Nuevo Mundo; y tercero, la historiografía humanista de la Europa renacentista. Se podría considerar que las dos primeras publicaciones garcilasistas, el Diálogos de amor y La Florida, establecieron al cronista como un traductor-autor dentro de la corriente intelectual del renacimiento europeo. Por ende, los Comentarios reales de los Incas ilustran el logro idóneo del Inca Garcilaso en el género historiográfico renacentista. Por ejemplo, la voz y la narrativa del género crónica predominan más notablemente en los Comentarios reales que en La Florida, ya que la primera obra no tiene una figura principal, tal como aparece en La Florida. Sin duda se presentan numerosos rasgos de la novela caballeresca en dichas obras, pero la esencia de los Comentarios reales es la historia cronológica de los líderes incaicos desde Manco Cápac. En el siguiente trabajo veremos cómo dicha crónica manifiesta una complejidad narrativa y genérica que engloba combinadas características de la historiografía española, indiana y renacentista.

\section{Palabras clave:}

crónica, historiografía, narrativa, Incas.

\section{Abstract}

Comentarios reales de los Incas is a text in which his author, Inca Garcilaso (1539-1616), displays talent and a special technique that are beyond dispute. Comentarios reales is a chronicle that represents the consolidation of skills of Garcilaso in the historiographic literary genre . 
This paper addresses the literary complexity of the narrative of Garcilaso in this capital text, which denotes a mixture of features pertaining to Spanish, Indiana and renaissance historiography

\section{Key words:}

Chronicle, historiography, narrative, Incas.

Los Comentarios reales del Inca Garcilaso (1539-1616) abarcan tres tradiciones historiográficas: primero, la tradición de crónicas españolas; segundo, la historiografía latinoamericana que comenzó después del "Descubrimiento" del Nuevo Mundo; y tercero, la historiografía humanista de la Europa renacentista. Se podría considerar que las dos primeras publicaciones garcilasistas, el Diálogos de amor y La Florida, establecieron al cronista como un traductor-autor dentro de la corriente intelectual del renacimiento europeo. Por ende, los Comentarios reales de los Incas ilustran el logro idóneo del Inca Garcilaso en el género historiográfico renacentista. Por ejemplo, la voz y la narrativa del género crónica predominan más notablemente en los Comentarios reales que en La Florida, ya que la primera obra no tiene una figura principal tal como aparece en La Florida. Sin duda se presentan numerosos rasgos de la novela caballeresca en dichas obras, pero la esencia de los Comentarios reales es la historia cronológica de los líderes incaicos desde Manco Cápac. En el siguiente trabajo veremos cómo dicha crónica manifiesta una complejidad narrativa y genérica que engloba combinadas características de la historiografía española, indiana y renacentista.

Los estudios críticos precedentes sobre el libro garcilasista se han enfocado en el vínculo a la escritura histórica posterior al descubrimiento del Nuevo Mundo y a la tradición filológica humanista. ' José Durand subraya que los Comentarios reales de los Incas es la "obra maestra de la historiografía indiana, comparable a los mejores frutos de la española" (1976: 48). Del mismo modo califica al cronista mestizo como un "clásico de América" y señala el carácter meticuloso del Inca Garcilaso al preparar los Comentarios reales: "[El Inca Garcilaso] mostraba agudo sentido crítico y hasta verdadera astucia en la exposición de sus ideas. Dueño de una apreciable cultura humanística - filosófica, histórica, literaria-, conocía ampliamente las ideas de su tiempo y de la antigüedad, y sabía usarlas con acierto..." (1976:

\footnotetext{
Existen incontables ensayos sobre los Comentarios reales, entre los cuales mencionamos sólo los siguientes: El Inca Garcilaso, clásico de América de José Durand, Historia, creación y profecía en los textos del Inca Garcilaso de la Vega de Enrique Pupo-Walker, Authority and Indigenous History in the Comentarios reales de Margarita Zamora, "The Law of the Letter: Garcilaso's Comentarios" (el capítulo dos de su libro Myth and Archive) de Roberto González Echevarría.
} 
58). Durand se preocupa por elucidar la destreza literaria de Garcilaso, equiparable a la de sus contemporáneos humanistas. El crítico Pupo-Walker, en Historia, Creación y Profecía en los textos del Inca Garcilaso de la Vega, analiza las narrativas testimoniales y autobiográficas de la obra garcilasista en el contexto de la historiografía latinoamericana. Pupo-Walker señala: "Estamos con toda seguridad, ante un texto que es materia primordial de la historiografía americana..." (1982: 85). Compara los Comentarios reales con otras principales crónicas indianas: "La centralidad de la persona de Garcilaso en los Comentarios le hace aparecer, en pasajes muy numerosos, como garante principal de la veracidad histórica. Es cierto que también harían autoridad de sí Bernal Díaz, Alvar Núñez y hasta Hernán Cortés" (1982: 96). A pesar de que las narrativas testimoniales y autobiográficas se destacan sólo en el "Proemio" de los Comentarios reales, el resto de la crónica garcilasista se dedica a la narración cronológica de la historia incaica desde la perspectiva objetiva en tercera persona. En Language, Authority and Indigenous History in the Comentarios Reales de los Incas, Margarita Zamora vincula estrechamente el texto del Inca Garcilaso a la tradición renacentista europea y analiza rastros filológicos humanistas en la escritura garcilasista. Zamora expone que el cronista mestizo andino se apropia de un poder como autor-narrador a través de su auto-identificación como un auténtico quechua-parlante. Zamora añade, además:

Historiographic authority in the Comentarios reales is founded on a concept of language that is clearly of humanist origin. As we have seen, text restoration and interpretation based on the philologic method of exegesis was at the heart of the humanist culture which reshaped Europe's intellectual landscape during the years of colonial expansion into the New World. (1988: 46)

De hecho, la filología ocupa una gran parte del humanismo renacentista y Garcilaso reitera su conocimiento de la lengua quechua para autentificar su voz narrativa. Sin embargo, la filología es una herramienta que facilita a uno comprender mejor las obras clásicas; es una hermenéutica, pero no una ideología. De ese modo es natural que Garcilaso se subscriba a la tradición renacentista humanista y se aproveche de los métodos filológicos para escribir su obra historiográfica. Zamora podría haber estudiado los Comentarios reales como una crónica dentro del contexto renacentista humanista cotejándolos con otras historiográficas compuestas por los contemporáneos del Inca Garcilaso. En The Law of the Letter: Garcilaso's Comentarios, Conzález-Echevarría indaga las relaciones entre el texto garcilasista y la escritura del Siglo de Oro español y, para empezar, considera que la narración cronística es casi idéntica a la narración picaresca:

One of the most significant changes in Spain, as the Peninsula was unified and became the center of an Empire, was the legal system, 
which redefined the relationship between the individual and the body politic and held a tight rein on writing.... [La narrativa legislativa] permeated the writing of history, sustained the idea of Empire, and was instrumental in the creation of the Picaresque. The way the Inca wrote, and the reason why he and other chroniclers wrote, has a great deal to do with the development of notarial rhetoric that resulted from the evolution and expansion of the Spanish State. To write was a form of enfranchisement, of legitimization. The picaro, the chronicler, and in a sense the whole New World, seek enfranchisement and validation of their existence through the writing of their stories. (1990: 45-46)

Pareciera una nota más genérica que específica, teniendo en cuenta de que este crítico reconoce que la narrativa legislativa no se resalta tanto en los Comentarios reales. González-Echevarría escribe:

Most readers of Garcilaso's Comentarios reales de los Incas would be hard put to identify Garcilaso's book with notorial rhetoric or with the Picaresque, but this is because only the first part of the work is commonly read. That is the part dealing with Garcilaso's Incaic background; it is a history of pre-Hispanic Peru, particularly the succession of the Inca monarchs until the arrival of the Spaniards, and a thorough account of Inca culture, specifically their religious beliefs.... Yet this second part [Historia general del Perú] is essential to the book's plan, perhaps the very spark that inspired the Inca to write. (1990: 71)

Aunque al comienzo hubo un intento por parte del crítico de estudiar las obras garcilasistas con relación a los escritos españoles del Siglo de Oro, los Comentarios Reales parecen escaparse de ese análisis.

Los mencionados cuatro críticos han analizado el texto garcilasista dentro del contexto de los escritos españoles de los siglos XVI y $X V I I$, pero no lo han estudiado como una obra representativa de la larga tradición de la historiografía española. Por ende indagaremos a tres aspectos significativos de los Comentarios reales: i) la narrativa universal-nacionalista; ii) la narrativa testimonial; iii) la influencia de la historiografía humanista renacentista. Para entrar en el análisis de estos temas se debe tener en cuenta ante todo que los Comentarios reales sucede a una extendida tradición del género crónica español. Entre varias características de los escritos cronísticos, el rasgo nacionalista distingue la historiografía española de las otras tradiciones historiográficas europeas (Thompson 1942: 144-45). Entre la época medieval y la renacentista, España celebró una proliferación de obras históricas nacionalistas, comenzando desde San Isidoro hasta Alfonso $X$ y pasando luego a los monarcas católicos. En los Comentarios reales 
Garcilaso no describe meramente eventos cronológicos tal y como sucedieron sino los narra como hechos memorables de la gran historia incaica. Al mismo tiempo el cronista mestizo hace hincapié en destacar que la historia de los Incas merece ser parte tanto de la historia española como de la historia universal. En cuanto a la influencia de la historiografía indiana en los Comentarios reales, Garcilaso autentifica su voz narrativa en el espacio textual aprovechando las narrativas testimoniales y autobiográficas que instrumentalizan los historiadores coloniales desde Cristóbal Colón como la innegable autenticidad de autor-testigo. No obstante, el Inca Garcilaso escribe su crónica no como un participantetestigo de la conquista española sino como un producto del encuentro violento entre los europeos y los indígenas. Garcilaso relata la historia de los Incas desde el punto de vista indígena y desde la voz narrativa personal. Al mismo tiempo, el escritor peruano revela su predilección por el género crónica antes que por la poesía o la ficción. Esta inclinación genérica manifiesta que Garcilaso comparte la pasión intelectual de sus contemporáneos humanistas por escribir obras historiográficas infiriéndolas como el máximo logro de la intelectualidad renacentista. A través del análisis de los tres aspectos que se han mencionado sobre la crónica garcilasista, se podría entender mejor la complejidad de los Comentarios reales.

\section{Los Comentarios reales y la historiografía española}

El Inca Garcilaso declara en el "Proemio" de los Comentarios reales: "Forzado del amor natural de la patria, me ofrecí al trabajo de escribir estos Comentarios" (1967: 59). El autor afirma su vínculo íntimo con el imperio inca y promete escribir "solamente del Imperio de los Incas, sin entrar en otras monarquías, porque no [tiene] la noticia dellas que désta" (1967: 60). De modo similar, en el segundo capítulo del Libro I, Garcilaso reitera que sólo va a hablar sobre la historia del Perú:

Y lo mismo se puede decir de las mieses, legumbres y frutas, tan diferentes de las de acá, que con razón le Ilamaron Nuevo Mundo, porque lo es toda cosa, así en los animales mansos y bravos como en las comidas, como en los hombres, que generalmente son lampiños, sin barbas. Y porque en cosas tan inciertas es perdido el trabajo que se gasta en quererlas saber, las dejaré, porque tengo menos suficiencia que otro para inquirirlas. Solamente trataré del origen de los Reyes Incas y de la sucesión dellos, sus conquistas, leyes y gobierno en paz y en guerra. (1967: 69).

Esta reticencia marca un contundente cambio de voz narrativa, en particular, en comparación con La Florida, en la cual Garcilaso asume el papel narrativo de representante de los amerindios sin hacer distinción 
entre los indígenas de la Florida y los otros indígenas del resto de América. ${ }^{2}$ En los Comentarios reales Garcilaso no propone trazar una historia general del Nuevo Mundo sino que se limita a narrar la historia de su tierra natal. Se distancia de muchos cronistas coloniales que pretenden componer una historia enciclopédica de América y se presenta como narrador-historiador de manera muy semejante a los autores de las crónicas tradicionales españolas que produjeron obras de la historia nacional.

En España, aun desde el periodo medieval, entre los cronistas ya había existido una enérgica tendencia por escribir la historia nacional (Thompson 1942: 144-45). Por ejemplo, entre los historiadores españoles medievales destaca la figura de San Isidoro (560-636), que escribió la Historia de regibus Gothorum, Vandalorum et Suevorum. San Isidoro exaltó su amor a la patria desde la primera oración en su conocido proemio "De Laude Spaniae" de dicho libro: "Omnium terrarum, quaeque sunt ab occiduo usque ad Indos, pulcherrima es o sacra, semperque felix principum, gentiumque mater Hispania" (1844-1855). Sánchez Alonso expone el sentimiento patriótico de esta oración:

No faltan en la historiografía anterior, incluso en la clásica y en pluma de extraños, elogios de nuestro solar de sus habitantes. Pero es totalmente nuevo el tono de fervorosa admiración con que el Santo se dirige a su España, dando una nota de entusiasmo patriótico, admirable en este tiempo. (1944: 72)

La glorificación de San Isidoro tal vez no parecería nada nuevo. Sin embargo, esta exaltación de España se podría percibir entusiasta y patriótica si se tiene en cuenta de que este santo pregonó dicha oración durante la época en la que la mayoría de sus contemporáneos se dedicaron a escribir historias religiosas agustinas ${ }^{3}$. Mitre Fernández explica:

La admiración que el Imperio Romano despierta en Isidoro es similar a la de un Eusebio de Cesarea, por cuanto ha sido el organismo a través del cual se ha propiciado la propagación del cristianismo.... El interés, sin embargo, que por la historia peninsular muestra Isidoro ha permitido hablar de una especie de "conciencia histórica

\footnotetext{
2 En varias partes de La Florida Garcilaso narra las costumbres culturales de los indígenas sin hacer distinción entre ellos. Por ejemplo, en el capítulo tercero del Libro V y el capítulo segundo del Libro VI Garcilaso subraya las similitudes entre los indígenas de La Florida y los del Perú en cuanto a sus supersticiones y a sus técnicas para construir canoas.

${ }^{3}$ Según Mitre Fernández, San Isidoro no ignoró completamente la historiografía religiosa agustina: 'No es menor el peso de la tradición agustiniana en San Isidoro. La división del proceso histórico se articula también en seis etapas, en cada una de las cuales se recogen algunos de los acontecimientos más destacados. Al referirse a la última edad, se dirá que 'lo demás que queda de la sexta edad sólo es conocido por Dios.' Línea agustiniana que se reforzará por la conciencia de un providencialismo que se quiere plasmar en la estricta equivalencia entre premios y castigos" (1982: 59).
} 
nacional," que iría reforzada por la exaltación poética de la "Laus Hispaniae." Pese a todo, la Historia de los godos, vándalos y suevos es una "historia nacional" sólo en tanto va ceñida esencialmente a los avatares de un pueblo -el visigodo-que acaba identificándose con el territorio peninsular. (Mitre Fernández 1982: 59)

Sin apartarse demasiado de los escritos históricos religiosos y romanos, San Isidoro logró narrar las memorias relativamente recientes de sus antepasados bárbaros y reivindicarlas, comparándolas a la historia de los romanos. Este santo continuó expresando celos patrióticos en su otra obra, Chronica regum visigothorum, tributada a la historia del reino visigodo en la Península Ibérica. Las crónicas de San Isidoro han evocado compasión nacionalista en los cronistas españoles posteriores, y la vigencia de las obras isidorianas fue indeleble en la tradición cronística medieval de España. Incluso durante la dominación musulmana el interés en la historia nacional no se suprimió completamente. Según Sánchez Alonso, varios cronistas imitaron y revivieron la pasión de San Isidoro a través de la historia visigoda, incorporándola como parte esencial de la historia de la Península Ibérica: ${ }^{4}$

Continuaron en vigor las que denominamos universal-nacional y nacional, si bien la primera limita casi del todo la noticia extrapeninsular a lo antiguo, circunscribiéndose ya a España en la época visigoda y tendiendo en la hispanoárabe a concretarse en Asturias-LeónCastilla. Pero ahora ambas ramas están tan entrecruzadas, se nutren tan abundantemente la una de la otra, que es preferible prescindir de examinarlas separadamente y formar con las de ambos grupos una serie común, para considerarlas por el orden en que fueron compuestas. (1944: 95-96)

Entre los múltiples textos enfocados en la historia nacional después de San Isidoro, merecen nuestra mención las crónicas compuestas por el rey Alfonso X-la Estoria de España (1270-1275) y la General Estoria (12751280). Alfonso el Sabio, con su aspiración política a ser el soberano del Imperio Sacro Romano, compila la Estoria de España. A lo largo de dicha crónica se narra una grandiosa e impresionante historia nacional elevada a la historia universal:

Nós don Alfonsso, por la gracia de Dios rey..., mandamos ayuntar quantos libros pudimos auer de istorias en que alguna cosa contassen de los fechos d'Espanna..., compusiemos este libro de

\footnotetext{
${ }^{4}$ Las siguientes crónicas pueden servir como ejemplo de la continuación de la historiografía nacional de San Isidoro: la Crónica mozárabe de 754, la Crónica Albeldense (del siglo IX), y la Crónica de Alfonso III de León (del siglo X) (Sánchez Alonso 1944: 101, 104, y 109, respectivamente).
} 
todos los fechos que fallar se pudieron della desdel tiempo de Noé fasta el nuestro. Esto fiziemos por que fuesse sabido el comienço de los espannoles et de quáles yentes fuera Espanna maltrecha...; cómo fueron los cristianos después cobrando la tierra...; después cuémo la ayuntó Dios, et por quáles maneras et en quál tiempo, quáles reyes ganaron la tierra fasta el mar Mediterráneo; qué obra fizo cada uno assí cuémo uinieron unos empós otros fastal nuestro tiempo. (Alfonso X 1955: Prol, I. 4)

Se percibe una evolución significativa desde la historiografía isidoriana. España ya no es simplemente una tierra de los reyes visigodos; más bien se despliega el legado histórico de España de manera excesiva. Brancaforte aclara, "La historia de España, o mejor dicho, del espacio geográfico de la Península Ibérica, está vista dentro del cuadro más amplio de la historia del Mediterráneo, de Roma en particular y de la historia universal" (1990: 22). La General Estoria continúa la misma tendencia universalista, pero engloba materiales más extensos: "Se transparenta en la General Estoria la admiración, el profundo respeto por todo lo que ha hecho, pensado e imaginado el hombre a lo largo de su historia, sin distinción de culturas y religiones" (Brancaforte 1990: 24). Alfonso $X$ organiza el mundo de la Europa de su época desde su propia perspectiva, abarcando múltiples historias y fuentes:

Alfonso was acting within the framework of a Spanish tradition in which it was the Moors and Jews, not the clerks, who embodied the idea of intellectual achievement.... It was, of course, very much his own, but its revolutionary feature was an anticipated "humanism" which for the first time accepted non-Christian learning on an equal footing with Western traditions. His cultural concept embraced the East and the West, but was indebted to the former for the very idea of learning as well as for radically new ways of perceiving both man and nature. (Márquez Villanueva 1990: 81)

La conciliación cultural que apreció Alfonso X incitó a su equipo de estudiosos historiadores a cotejar y combinar diferentes visiones del mundo, así como heterogéneas narrativas de la historia ecuménica. Los cronistas de la época de Alfonso $X$ se alinearon con la posición intelectual alfonsina para escribir la historia de España como una parte inherente de la historia mundial universalista. Esta tendencia universalista de la historiografía española, aunque se descontinúa por un cierto periodo después de Alfonso X, regresa cuando los Reyes Católicos retoman la tradición cronística universalista. El crítico Gingras dice que Sancho IV, el hijo de Alfonso X, y sus sucesores no mostraron afán de historicismo universalista:

Almost immediately after Alfonso X's death, his factually oriented and universalizing model of historical writing suffered a reversal. The 
new generations of historians, lacking Alfonso's critical vision, gave increasing importance to descriptive detail and the use of literary ornamentation. (1990: 419)

Con esta afición por los detalles descriptivos se podía profundizar y particularizar cada hecho y periodo históricos, pero a la vez, se podía descuidar la comprensión y compasión cultural del historicismo universalista. Los Monarcas Católicos, Fernando e Isabel, renovaron la pasión por la historiografía universalista porque la expansión imperialista llegó a un momento casi climático por la reconquista completa de la Península Ibérica y por la expedición a América. El aumento territorial impetuoso implicó la difusión de la ideología religiosa española, tanto como la necesidad de autodefinición como factor dominante en las tierras reconquistadas y en el mundo recién descubierto. De este modo, numerosos cronistas de los reyes católicos miraron hacia más allá de su historia nacional y crearon una continuidad histórica entre la época medieval de España y la contemporánea de los Reyes Fernando e Isabel. Joan Margarit i Pau (1422-1484), el historiador conocido como el Gerundense, escribió un resumen de la historia española desde los tiempos pre-helénicos hasta la estancia de Augustus en España. En la dedicación de sus Paralipómenos a los Monarcas Católicos, el Gerundense expresó su "admiración por la unidad que [los reyes Fernando e Isabel] han procurado a España" y anotó el "contraste entre su actividad [de los Monarcas Católicos] y la desidia de los demás reyes cristianos, que permitió los avances del Turco" (Sánchez Alonso 1944: 364). Del mismo modo, Diego de Valera (1412-1488), un contemporáneo del Gerundense, escribió la Crónica de España, donde se trató el reinado de Enrique IV y de los Reyes Católicos (Sánchez Alonso 1944: 367), mientras que otro coetáneo del mismo Gerundense, Alfonso de Palencia (1423-1492) trabajó temas semejantes en sus "Décadas" (391). Estos tres cronistas ilustres coincidieron en conceptualizar la historia española como la columna vertebral de la historia mundial universal, para luego delinear su época contemporánea de los reyes Fernando e Isabel como el momento culminante de toda la historia universal.

El Inca Garcilaso de la Vega se impregna de esta tradición de historiografía nacional y universalista desarrollada desde San Isidoro hasta la época de los Monarcas Católicos. En los Comentarios reales Garcilaso presenta la historia inca desde el mito fundacional de Manco Cápac hasta el fin trágico causado por la llegada de los españoles. A lo largo de los Comentarios reales el autor andino intenta equiparar la historia inca con la romana y también trazar paralelismos entre la historia española y la incaica. Estas comparaciones garcilasistas sugieren que la historia de los Incas merece considerarse como parte de la historia española, latinoamericana y universal. 


\section{Los Comentarios reales y la historiografía indiana}

La historiografía patriótica isidoriana y la universalista alfonsina confluyen en la formación genérica de la historiografía indiana. Además de dichas tendencias medievales, una nueva estrategia narrativa emerge en las crónicas indianas: el discurso testimonial. Al proporcionar informaciones de las tierras no exploradas a su audiencia europea, los autores de la historiografía indiana se benefician de sus experiencias como participantes y testigos en el proyecto de la conquista y colonización de América; asimismo, el discurso testimonial le otorga a cada cronista el poder narrativo. Garcilaso también aprovecha el discurso testimonial; no obstante, su uso de la experiencia testimonial parece ser distinto al modo con que aprovechan los cronistas españoles la voz testimonial. Mientras que los narradores españoles utilizan sus relatos testimoniales para participar en el acto de crear la historia de la conquista de América, Garcilaso dispone su discurso testimonial como un sujeto indígena para ofrecer el otro lado de la historia oficial de la conquista española.

Antes de indagar en el análisis del discurso testimonial en los Comentarios reales, se debe reflexionar sobre el concepto de testimonio. Según Achugar, la etimología del término testimonio viene de una palabra griega, "mártir," que significa "el que autentica, atestigua o confirma algo," suponiendo que uno que ha vivido o ha estado presente en tal incidente (1992: 59). La palabra original griega no contiene la connotación de sufrimiento o sacrificio, pero cuando se transmite al latín y, en particular, cuando matizada por la cristiandad, su significado se transforma a lo que entendemos hoy en día como testimonio del mártir. Por ende, el testimonio se convierte en el relato de la vida ejemplar:

La vida del mártir es ofrecida en la narración biográfica como un ejemplo a respetar y eventualmente a seguir; es decir, la narración de su vida es ofrecida como una conducta moral ejemplar y ejemplarizante. La relación testimonio-mártir destaca el aspecto moral ejemplarizante y muestra que el relato testimonial de dicha vida aspira a cumplir, y de hecho así funciona, una función ejemplarizante en una determinada comunidad. (Achugar 1992: 59)

Tras modificar este discurso testimonial del martirio, los conquistadores españoles narran sobre sus expediciones como un ejemplo de pasión religiosa y de dedicación patriótica desde una perspectiva pseudo-martirio. En su espacio narrativo ellos frecuentemente se identifican como héroes o protagonistas del drama histórico de la conquista de América, puesto que supuestamente han corrido graves peligros en circunstancias precarias sólo por conservar la fe católica y por exaltar la lealtad patriótica (Pastor 1988: 29). Por esta razón, sus hazañas y vidas se pueden presentar como 
modelos. Tal manifestación literaria se presenta abundantemente en la historiografía del Nuevo Mundo. Estos ejemplos se pueden encontrar no sólo en los escritos de Colón y de Cortés sino también en los escritos de los conquistadores con un origen más humilde, como Bernal Díaz, y también en los de los exploradores fracasados como Cabeza de Vaca. Subrayando su estado como un legítimo participante en la conquista de México, Bernal Díaz insiste en la veracidad de sus escritos sobre los de López de Gómara, a quien acusa de componer La conquista de México sin presenciar la misma:

Miren los curiosos lectores cuánto va de la verdad a la mentira, (de su historia [ La conquista de México]) a esta mi relaçión en decir letra por letra lo acaecido, y no miren la retórica y ornato, que ya cosa vista es que es más apacible que no ésta grosera, mas resiste la verdad a mi mala plática y pulidez de retórica con que ha escrito. (1987: Cap. CXXIX, 247)

La sofisticación retórica no concierne a Bernal Díaz, y, según su modo de ver, la elaboración retórica implica una supuesta exageración y fabricación de lo real y lo verdadero. Bernal Díaz justifica y ratifica que la simplicidad y veracidad deben ser las características primordiales de la narración testimonial. En sus escritos la simplicidad narrativa se convierte en una calidad moral, por lo cual la crónica de Gómara es tan errónea como inmoral, ya que Gómara mintió en su obra La conquista de México. Tal superioridad moral permite a Bernal Díaz engrandecerse como el narrador primario y fidedigno: "Y digo otra vez que yo y yo y yo, dígolo tantas veces, que soy el más antiguo" (1962: Cap. CCX, 539). Este enfático "yo" narrador como testigo parece estar determinado en participar en el evento de crear la historia, es decir, la historia de la conquista de América, para recalcar la autenticidad de su testimonio y a la vez, por hacer sus escritos como la trascendental fuente de la conquista española.

Mientras que Bernal Díaz, un soldado de origen humilde, reclama la absoluta legitimidad de su testimonio, Alvar Núñez Cabeza de Vaca, quien sufrió desastrosos naufragios, dice, asimismo, que merecen ser narradas y reconocidas la expedición fracasada en la que participó y la peripecia que tuvo para sobrevivir en América. En su obra Naufragios y Comentarios se dirige primero a su lector - al rey de España- para reclamar su servicio a la patria y al monarca:

De mi puedo dezir que en jornada que por mandado de vuestra magestad hize en tierra firme, bien pense que mis obras y servicios fueran tan claros y manifestos como fueron los de mis antepassados: y que no uviera yo necessidad de hablar para contado entre los que con entera fe y gran cuydado adminstran y trantan los cargos de vuestra magestad y les haze merced. (Nuñez Cabeza de Vaca 1906: Proemio) 
A pesar de su fracaso, el conquistador insiste en su orgullo por haber participado en la conquista de América y por haber servido a la patria. Muestra el valor de su experiencia por haber sobrevivido a la deshumanización total de un servidor del monarca: haber tolerado las calamidades de la expedición y su vida en esclavitud bajo los indígenas:

[T]raer a vuestra magestad relación de lo q[ue] en diez años q[ue] por muchas y muy estrañas tierras que anduve perdido y en cueros, pudiesse saber y ver, ansi en el sitio de las tierras y provincias y dista[n]cias dellas como en los mantenimientos y animales que en ellas se crían, y las diversas costumbres de muchas y muy bárbaras nasciones con que converse y viví, y todas las otras particularidades que pude alcançar y conocer que dellos en alguna manera vuestra magestad será servido. (Nuñez Cabeza de Vaca 1906: Proemio)

Después de haber vivido bajo esa barbarie, el conquistador aparece en su texto casi como un mártir de la expedición, alguien que hizo todo lo posible para no perder su fe cristiana y mantenerse fiel a la corona. Por ende, su testimonio sobre los hechos fracasados de la expedición aparecería ante los ojos inquisitoriales de los españoles como una acción ferviente de un leal y pobre siervo, un ejemplo de mártir de la conquista española.

Si bien las narraciones testimoniales de los conquistadores españoles revelan un deseo por ser parte de la historía oficial de la conquista de España, Garcilaso se identifica a sí mismo como indiano y pretende narrar la otra cara de la historia de la conquista, que es la historia oficial del Perú. En el capítulo titulado "Protestación del autor sobre la historia" Garcilaso declara:

[M]e dio aquel Inca con la relación de otros muchos Incas e indios naturales de los pueblos que este primer Inca Manco Cápac mandó poblar y redujo a su Imperio, con los cuales me crié y comuniqué hasta los veinte años. En este tiempo tuve noticia de todo lo que vamos escribiendo, porque en mis niñeces me contaban sus historias como se cuentan las fábulas a los niños. Después, en edad más crecida, me dieron larga notica de sus leyes y gobierno.... Demás de habérmelo dicho los indios, alcancé y vi por mis ojos mucha parte de aquella idolatría, sus fiestas y supersticiones.... [V]í muchas cosas de las que hacían los indios en aquella su gentilidad, las cuales contaré diciendo que las vi. (1967: Libro I, Cap. 19, 110-1)

Garcilaso no se presenta como un sujeto que ha vivido un momento difícil, más bien se muestra como un testigo vital que ha sobrevivido a todo tipo de eventos y detalles históricos, alguien que advierte e instruye sobre la cultura Inca. El cronista peruano manipula eficientemente su discurso en los Comentarios reales para reclamar una historia que podríamos llamar "anti-oficial" de la conquista española. En otras palabras, Garcilaso propone 
una crónica de la historia indígena, frecuentemente relegada, distorsionada o marginada por los historiadores españoles. Achugar apunta, de hecho, los elementos contradictorios del discurso testimonial:

[E]I hecho mismo de existencia del mártir conlleva la existencia de aquel o aquellos que convierten al individuo en mártir. Aquellos se sienten amenazados su poder con la conducta del mártir, ya sea a nivel individual como a nivel social. Esto apunta a algo tratado anteriormente, en relación al vínculo entre testimonio e historia otra o historia alternativa. La biografía sobre el mártir y el testimonio aparecen de este modo cumpliendo una función de contra historia ejemplarizante que el biógrafo o mediador del testimonio asumen conscientemente. (1992: 59)

En el caso del individuo mártir, existe un roce de poderes opuestos y si se concibe la conquista española como un martirio implícito, se pueden reconocer dos poderes en contra y, por tanto, dos versiones del hecho: la del martirizado y la del opresor. En varios testimonios ofrecidos por los conquistadores españoles, sus experiencias autobiográficas fueron descritas de manera semejante al testimonio-martirio. Los españoles se autoconstituyen como los seres que han sobrevivido los horrendos eventos para mantener su fe religiosa y su lealtad a la patria, mientras que se describe a los indígenas como los antagonistas que les han impuesto un peligro que los amenaza. Basándose en sus testimonios los conquistadores españoles crean y organizan su versión de la historia oficial y ejemplar de América y suprimen el lado indígena de esta historia. No obstante, tal proceso narrativo se trastorna en los Comentarios reales porque Garcilaso utiliza su testimonio como superviviente de la cultura inca y compone la historia de la cultura materna conquistada, reivindicando, así, la voz de los suyos.

\section{Los Comentarios reales de Garcilaso y la historiografía humanista}

Si bien los Comentarios reales, en conexión con la historiografía española e indígena, revelan que la narrativa garcilasista adopta y modifica universalmente la historia nacional y la narrativa testimonial, el análisis de su trabajo en relación al humanismo renacentista europeo nos ayudará a comprender la producción literaria del autor en el contexto de sus intelectuales contemporáneos. Dado que el peruano mestizo escribe durante el Siglo de Oro -el periodo más fructífero en producciones de poesía, teatro y novela-, parece curioso que todas sus obras, excepto por el Diálogos de amor, sean obras históricas. En La Florida, el autor brevemente recalca su cambio de interés en las obras ficcionales, en particular las novelas caballerescas:

[T]oda mi vida - sacada la buena poesía - fui enemigo de ficciones como son libros de caballerías y otras semejantes. Las gracias de esto 
debo dar al ilustre caballero Pedro Mejía, de Sevilla, porque con una reprehensión, que en la Heroica obra de los Césares hace a los que se ocupan en leer y componer los tales libros, me quitó el amor que como muchacho les podía tener y me hizo aborrecerlos para siempre. (1956: Libro II, Parte I, Cap. 27, 112).

Durand también confirma la destacada ausencia de las novelas caballerescas en la lista de inventarios de la colección de la biblioteca del Inca Garcilaso (1947: 263-64). A pesar de que Garcilaso nunca ostenta específicamente su preferencia por el género crónica, debe estar muy consciente de la alta estima que tienen sus contemporáneos humanistas por los escritos historiográficos. Kelly brinda una teoría donde se puede apreciar cómo el Renacimiento europeo fue visto en el campo de la historia para su estudio:

Through the classical revival [history] became a liberal art and a literary genre; through the Reformation it became a surrogate for the tradition of 'true religion'; through the Counter-Reformation controversy it became a highly organized argument in the later sixteenth century, and its significance for the contacts with philosophy increased accordingly. (1988: 746)

Kelly encuentra este tipo de evaluación humanística histórica en la historiografía española:

The largest claims on behalf of history had been made by that archrhetorician Lorenzo Valla in his history of Ferdinand of Spain [De rebus a Ferdinando Hispaniarum rege...gestis]. "History is more robust than poetry because it is more truthful," Valla argued. "It is oriented not towards abstraction but toward truth...[and] teaching by examples." It was even superior to philosophy, since "the discourse of historians exhibits more substance, more practical knowledge, more political wisdom..., more customs and more learning of every sort than the precepts of any of the philosophers." (1988: 749)

Garcilaso pertenece a este pequeño grupo de intelectuales que tiene un trasfondo cultural definido, que puede ser corroborado por la colección de su biblioteca privada, con numerosas obras de historia europea y del Nuevo Mundo, obras clásicas y de la tradición cristiana (Durand 1947: 261). Además, durante la época en que fueron publicados los Comentarios reales (1609), el prestigio de las producciones históricas era mayor que nunca: "By the end of the sixteenth century history had, in the eyes of many observers, attained a position of eminence, sometimes elevated above other disciplines, since it was regarded as the source and even the ordering principle of knowledge" (Kelly 1988: 759). Teniendo en cuenta el contexto cultural desde donde escribe Garcilaso su obra de los Comentarios reales, podemos discutir dos cuestiones. La primera recae en el mismo título, lo que nos 
lleva a preguntarnos porqué se titula "comentarios." Segundo, aunque no era frecuente escribir trabajos históricos en dicha época en España, todavía seguía vigente escribir los relatos históricos en latín por ser considerados éstos más formales debido a su carácter notarial. Por tanto, deberíamos buscar la razón por la cual Garcilaso decide prescindir el latín.

Con relación al título de la obra garcilasista, debemos abordar el significado de "comentario." Porras Barrenechea explica:

Entre las diversas formas históricas adoptadas por la historia clásicahistorias, anales, memorias, comentarios - la elegida por el Inca es la de menor categoría. "Comentarios, dice Cicerón, son simples notas conmemorativas"... El Inca no se atreve a abordar los grandes géneros y escoge el menos ostentoso. Los comentarios son breves notas o glosas a noticias ajenas que no requieren gran ingenio ni preparación. (1993: 227)

Zamora amplía la definición de "comentario" en el contexto renacentista:

The historical commentary typically dealt with events contemporary with its author. In fact, it was a sort of catalogue of events intended for the use of future historians.... If differed from history in that it had the chronological limits of the author's lifetime, it was not bound by a theme or thesis, it could therefore include a variety of events and historical actions. Its primary purpose was to inform, to transmit information to future historians... (1988: 52).

La obra de Garcilaso quizás describa una noción algo vaga de esta definición de "comentario," no obstante debemos entender que posiblemente el autor escogió ese título por la flexible nota genérica que le proporcionaba, y de ese modo tomar ventaja de todos los elementos imaginarios y alusiones del término. Los Comentarios reales contienen frecuentes digresiones y ofrecen una enciclopédica información sobre la cultura andina. A través de su obra, Garcilaso intenta rememorar y destacar una gran cantidad de temas concernientes al Perú. En el siguiente texto, el autor andino declara:

[M]e ofrecía al trabajo de escribir estos Comentarios, donde clara y distintamente se verán las cosas que en aquella república había antes de los españoles, así en los ritos de su vana religión como en el gobierno que en paz y en guerra sus Reyes tuvieron, y todo lo demás que de aquellos indios se puede decir.... (Vega 1967: 59)

Podemos destacar que del capítulo 9 al 25 del Libro VIII, Garcilaso enumera una extensa variedad de animales, plantas, vegetales, minerales y muchos otros recursos naturales que se encuentran en los Andes, mientras que desde el capítulo 15 al 30 del Libro IX se describen animales, frutas y granos que fueron traídos de España y comenzaron a abundar en las tierras 
peruanas. Por un lado, el insistente deseo garcilasista de representar aspectos heterogéneos de la historia y cultura del Perú, acentúa el análisis de Lorenzo Valla, quien insiste en la superioridad histórica sobre cualquier otro estudio humanístico. Recordemos que para Valla, la historia "exhibits more substance, more practical knowledge, more political wisdom..., more customs and more learning of every sort than the precepts of any of the philosophers" (Kelly 1988: 749). ${ }^{5}$

Por otro lado, Garcilaso se enfrenta a un dilema similar al de Cristóbal Colón cuando intentó de describir la gente del Nuevo Mundo y su tierra, tan diferente en contraposición a lo visto en Europa. Por eso, como Colón, el escritor peruano recurre al discurso retórico de la "abundancia," que, de acuerdo a Ortega, emerge de la dificultad de describir la extraordinaria riqueza de América (1988: 101-107). Esta exuberancia superaba los límites de la imaginación del discurso narrativo familiar para la audiencia europea. Hacia un intento por mantener una unidad discursiva que represente al Nuevo Mundo, el narrador comienza a construir su descripción de una heterogeneidad inmensurable y de una abundancia increíble. Ortega señala que "Desplazando la escritura del lugar ameno por la del espacio abundante, Colón inscribe... un gesto que será una práctica sistemática del Inca Garcilaso" (1988: 106-107). Desde esta perspectiva "El Libro [Los Comentarios reales] será el espacio final de las sumas..., de las lenguas y las culturas, de los objetos del viejo y del nuevo mundo" (1988: 108). De hecho, la elección de Garcilaso del título de su obra "Comentarios" le facilita variedad de temas y discursos dentro del periodo histórico al que pertenece. Además, como explica Porras Barrenechea, Garcilaso escoge el género secundario por ser un sujeto que pertenece a la escala de la minoría histórica.

El mestizo peruano fue uno de los primeros escritores representantes de Latinoamérica que recurrió al "discurso de la abundancia," en cuanto a su sentido de uso como creación de un nuevo estilo, cuyo axioma justifica la exuberancia de América.

Los Comentarios reales de Garcilaso representan una obra complicada por incluir tres tradiciones historiográficas: la española, la indígena y la europea renacentista. En cada una de estas tradiciones, el autor encuentra los elementos históricos que le sirven para componer la historia nacional del Perú. Además, la historiografía humanista del Renacimiento le enseña sobre la importancia de la tradición escrita. A pesar de esta gran influencia de los componentes europeos, no se debe olvidar que es la historiografía del Nuevo Mundo la que ofrece significativamente los instrumentos del discurso testimonial del Inca Garcilaso.

\footnotetext{
${ }^{5}$ Traducción de Valla, citado en Kelly.
} 


\section{REFERENCIAS BIBLIOGRÁFICAS}

ACHUGAR, Hugo. "Historias paralelas/historias ejemplares." En: Beverley, John et al (eds): La voz del otro: Testimonio, subalternidad y verdad narrativa. Lima y Pittsburgh: Latinoamericana Editores, pp. 49-71. 1992.

ALFONSO X. [c. 1275-1280] General Estoria. eds. Antonio G. Solalinde et al. Madrid: Centro de estudios históricos. 1930.

ALFONSO X [c. 1270-75] Estoria d'Espanna. Primera crónica general. ed. R. Menéndez Pidal. 2 vols Madrid: Gredos, 1955.

BRANCAFORTE, Benito. "Introducción." Alfonso X el Sabio. Madrid: Cátedra, pp. 11-29.

DÍAZ DEL CASTILLO, Bernal. Historia verdadera de la conquista de la Nueva España., México: D. F. Porrúa, 1962 [1632].

DURAND, José. "La Biblioteca del Inca." Nueva Revista de Filología Hispánica 2.2, pp. 239-64. 1947

DURAND, José. El Inca Garcilaso, clásico de América. México D. F., Sep setentas. 1976.

GINGRAD, Gerald. "The Medieval Castilian Historiographical Tradition." Romance Languages Annual 2, pp. 419-25. 1990

GONZÁLEZ ECHEVARRÍA. Roberto. Myth and Archive. Cambridge: Cambridge UP. 1990.

KELLY, Donald. "Renaissance Philosophy of History." En: Schmitt, Charles B. (ed). The Cambridge History of Renaissance Philosophy. Cambridge: Cambridge UP, pp. 746-61. 1998.

LEÓN HEBREO. Diálogos de amor. trad. Garcilaso de la Vega. Madrid: V. Suárez. 1949 [1590].

LÓPEZ DE GÓMARA, Francisco. La conquista de México, edición de José Luis de Rojas. Madrid: Historia 16. 1987 [1552].

MÁRQUEZ VILLANUEVA, Francisco. "The Alfonsine Cultural Concept." En: Márquez Villanueva, Francisco et al (eds). Alfonso $X$ of Castile the Learned King (1221-1284), Cambridge: the Dept. of Romance Lang. and Lit. of Harvard University, pp. 76-109. 1990.

MITRE FERNÁNDEZ, Emilio. Historiografía y mentalidades históricas en la Europa Medieval. Madrid: Editorial de la Universidad Complutense. 1982.

NÚÑEZ CABEZA DE VACA, Alvar. Relación de los naufragios y comentarios de Alvar Núñez Cabeza de Vaca. Madrid: V. Suárez. 1906 [1542].

ORTECA, Julio. "Para una teoría del texto latinoamericano: Colón, Garcilaso y el discurso de la abundancia." Revista de crítica literaria latinoamericana 14. 28, pp. 101-115. 1988.

PASTOR, Beatriz. Discursos narrativos de la conquista de América. Hanover: Ediciones del Norte. 1988.

PORRAS BARRENECHEA, Raúl. "El Inca Garcilaso de la Vega." En: Instituto de Investigaciones Cambio y Desarrollo (ed). Inca Garcilaso de la Vega, primer mestizo de América. Lima: Instituto de Investigaciones Cambio y Desarrollo, pp. 217-44. 1993 [1946] 
PUPO-WALKER, Enrique. Historia, creación y profecía en los textos del Inca Garcilaso de la Vega. Madrid: Porrúa Turanzas. 1982.

SAN ISIDORO DE SEVILLA [Isidorus Hispalensis]. 1844-1855 Historia de regibus Gothorum, Vandalorum et Suevorum, edición de Jacques-Paul Migne, Patrologia Latina Paris: Migne, vol. 83, col. 1057. Disponible en: http://www.forumromanum.org/literature/isidorus_ hispalensis/historia.html> 28/2/2009.

SÁNCHEZ ALONSO, Benito. Historia de la historiografía española. Madrid: CSIC. 1944.

THOMPSON, James. A History of Historical Writing. 2 vols. Nueva York: MacMillan, vol 1. 1942.

VALERA, Diego. Crónica de España. 1493

VEGA, Garcilaso de la. Historia general del Perú (Segunda parte de los Comentarios reales de los Incas). Buenos Aires: Amece editores S.A. 1944.

La Florida del Inca, edición de Emma Susana Speratti-Piñero. México: Fondo de Cultura Económica. 1956.

Comentarios reales de los Incas, edición de José Durand. Lima: Editores de

Cultura Popular. 1967.

ZAMORA, Margarita. Language, Authority and Indigenous History in the Comentarios reales de los Incas. Cambridge: Cambridge UP. 1988.

Song No Ph. D. (Universidad de California, Berkeley) es profesor asociado en Purdue University y codirector del Programa de Estudios Latinoamericanos. Ha llevado estudios en la Universidad Complutense de Madrid, en el Centro Bartolomé de las Casas, en la Universidad de Campiñas, Darmouth College y en la Universidad de Coimbra. Ha publicado Cien años de contrahegemonía: Transculturación y heterogeneidad. Lima, Universidad Nacional Mayor de San Marcos, 2008.; Comentarios reales. Edited with Elena Romiti, Montevideo, Universidad de la República, Uruguay, 2009; además, numerosos artículos en torno a Garcilaso, Pedro Zulen y, también, sobre cine latinoamericano.

sno1@purdue.edu 